1939

\title{
Psychogenic factor in asthma
}

W. A. Johnson

University of Nebraska Medical Center

This manuscript is historical in nature and may not reflect current medical research and practice. Search PubMed for current research.

Follow this and additional works at: https://digitalcommons.unmc.edu/mdtheses

Part of the Medical Education Commons

\section{Recommended Citation}

Johnson, W. A., "Psychogenic factor in asthma" (1939). MD Theses. 754.

https://digitalcommons.unmc.edu/mdtheses/754

This Thesis is brought to you for free and open access by the Special Collections at DigitalCommons@UNMC. It has been accepted for inclusion in MD Theses by an authorized administrator of DigitalCommons@UNMC. For more information, please contact digitalcommons@unmc.edu. 
THE PSYCHOGENIC FACTOR IN ASTHMA

BY

W. A. Johnson

Sentor Thesis

Presented to the University of

Nebraska College of Medicine

Omaha, 1939 
$\$ 81045$ 
TABLE OF CONTENTS

I. Discusgion of Problem Page

of Problem...........

II. Methods of Study............

III. Case Reports and Authors' Analysis................

IV. Summary of Case Reports.......39

v. Outline of Psychotherapy......4I

VI. General Summary...........42

VII. Conclusions.............43

VIII. Bibliography...........44 
"In its widest possible sense a man's self is the sum total of all that he can call his, not only his body and his psychic powers, but his clothes and his house, his wife and children, his ancestors and friends, his reputation and works, his lands and horses, and yacht and bank account."...James 
"Asthma is dyspnea of a characteristic "wheezy" type caused by obstruction to the flow of air in and out of the lungs. Such wheezy breathing occurs in a variety of conditions, and may be elther continuous or paroxysmal; hence the term asthma should be used not to indicate a disease, but a symptom. Bronchial asthma is a term which is loosely applied to such a syndrome exhibited by patients, who, between attacks, are subjectively and objectively well." This is substantially the definition given by Rackemann (1), one of the great clinicians of the symptom-complex. He reflects the attitude of the majority of the students on the subject. However, it will be seen that remissions are not necessarily free of symptoms, but may contain phenomena of psychologic character, the causes of which are closely allied with the entire course of the affection.

The purpose of this paper is to present the $\infty n-$ victions of a small group of practitioners who report that the psychological factor in the production, course and termination of the disease is of some importance. The recent advances in the study of allergens have so absorbed the energies of the medical group as to almost exclude the older theories of "nervous" causes which have persisted over hundreds of years, $(2,14)$.

Hansen (3), in a lecture before the Royal society of Medicine in 1929 expressed the following argument whi ch serves to delineate the issue and clarify the objective 
THE PSYCHOGENIC FACTOR IN ASTHMA

of the several investigators: "Organs are not separate entities, but are bound up in the physico-chemical unity of the functions. Hence we must consider the individual as a working organism. This view of the personality includes the psyche by which we are conscious of, and experience, both health and disease. Thus the pathology of the person must combine the physico-chemical functions with the psyche to be complete."

"We have no means of measuring the strength of psychical excitation, and no possibility of finding a psycho-somatic energy formula. The qualitative multiplicity of the forms of psychical excitation and expression, and their interpretation are a great danger to the method."

Methods of studying the relationship between the symptoms presented by the patient and his psychological background are inexact, to be sure, but a few investigators have attempted to form methods of attack at least qualitatively of sound character. Strauss $(4,7)$, has selected a large number of adults for superficial investIgation attempting to answer the following questions:

1. "Does the patient volunteer information that he is, generally speaking, "nervy", apart from his asthmap"

2. "Does he state that excitement or emotion of any kind precipitates an attack?"

3. "Does he habitually live under conditions involving excessive worry or emotional stress and strain?" 4. "Is his libidinal life reasonably and legitimately satisfied, or satisfiable judging by superficial 
THE PSYCHOGENIC FACTOR IN ASTHMA

standards alone?"

5. "Is he temperamentally a person who finds it difficult to adapt himself to the social environmentp"

6. "Are there any obvious pointers to determine "complexes" in the psycho-analytic sense?"

7. "Was he considered to be "nervous" as a childp"

8. "Is a crudely purposive (unconsdous factor easily detectable and probably a link in the causal change?

9. "Does the patient superficially impress the investigator as being "neurotic" or well balanced?"

10. "Is the family history neuropathic?"

The main objection to such an investigation is the large amount of subjective element entering into the evaluation of the results. But granted an ordinary amount of integrity on the part of the investigatior subjetive error need not seriously vitiate his judgement. Strauss conducts the investigation as follows: "The patients are instructed to present themselves at a certain hour without being told the nature of the investigation. Most patients thought it to be an ordinary routine affair. On first occasions, the patients are interviewed forty-five minutes. Many patients were not seen a second time, but voluntarily presented themselves to report progress.

"As a general rule, it was possible to obtain an impression of the patient, together with his history, without asking many leading questions. Suggestive questions were never asked. The patients were never given the idea 
THE PSYCHOGENIC FACTOR IN ASTHMA

that interviews were therapeutic in intent, yet in many cases, the interview was followed by distinct improvement in the patients conditions, judged by diminution in frequency or disappearance of the asthmatic attacks. Whether such changes are due to suggestion or result of mild degrees of "psychocatharsis" occurring with the interviews cannot be determined"; but on either hypothesis, such an improvement would favor the consideration of the psychic element in asthma.

For Strauss' system evaluation, he felt it to be necessary to give a large number of individual case histories (thirty), for the "results are not easily tabulated. Difficulties are excessive in giving a quantitative estimation of the psychic factor in each case. The patient was given marks for each positive answer to the questions above. A positive answer to \#I was valued at three marks, to \#2 and \#3 at 2 marks, to questions \#4-10 at one mark each. Hence the full score was fourteen". Dr. Strauss' report on results will be given later.

Hansen (5) and others, (6) report the use of hypnosis both in the skin testing for offending substances, and during the exposure to the specific allergen for the purpose of inducing an attack. All admit that "this form of treatment needs careful evaluation and should be considered as a symptomatic one and not a cure".(5)

Zeigler and Elliott (22) sought to obtain graphic evidence of the effect of emotions upon asthmatic breathing with the aid of the electrocardiograph and pheumograph tracings 
THE PSYCHOGENIC FACTOR IN ASTHMA

in nine asthmatics. Of these, six previously had some form of proven neurosis and three were sensitive cases with a normal neurologic history. Tracings were taken while the patients were at rest and then during periods in which they concentrated upon some disturbing thought. The results would seem to indicate whether psychic factors would be effective in producing the prolonged respiratory phase in the resplration curves and the slight elevation in pulse associated with asthmatic attacks, with the effects upon the hypersensitive cases as a control. This method is the victim of the whimsies of the patients, insufficient number of cases, absence of literature supporting the technique and the significance of the findings, as well as the lack of a coordinated general plan of attack.

Clarkson (6) gives the following plan of study of these patients:

1. "Skin tests as basis."

2. "Hypnosis with a repetition of skin tests with the most offensive substance."

3. "Psycho-analysis of a general type."

4. "Psychotherapy and its effect."

This method combines some of the most accepted procedures in general practice with a type of psychological study accepted only by the school based upon Freudian methods. It is acceptable by virtue of its embodiment of a routine procedure adaptable for all patients.

A great many investigators have noted the emotional states produced by the summation of allergic effects, 
THE PSYCHOGENIC FACTOR IN ASTHMA

$(6,9,10,11,12,15,19,32,33)$, and some base their judgement as to the effectiveness of the cure by the absence of both the specific symptoms of asthma and the emotional upsets. However, in cases where the allergic factor is absent, estimated at from thirty to sixty percent by different authors, $(17,77)$; /express a lack of confidence in the method and success of treatment.

Many investigators who, upon a cursory examination of the case, determine that the psychogenic factor is predominant, give injections of sterile water, (8), or other placebos, guiding their treatment by the success of impressing the patient subsequently. These practices frequently lack coordination and purpose, leaving the investigator with a positive opinion but without definite chart for evaluating the results on a series of patients.

Gillespie (13), rates his cases of asthma psychoneurotically by the following criteria:

1. "On "constitution" of the patient.

2. "On accident of time: 1.e. Hurry plus breathlessness, plus mental stress produces original attack of asthma, etc.

3. "Whether patient can be shown to have had a pre-existing fear of lung disease.

4. "Whether patient can be proven to have given undue attention to the lungs or had an "impression of (Adlerian) organ inferiority" arising from pre-existing lung disease such as bronchitis, etc. 
THE PSYCHOGENIC FAOTOR IN ASTHMA

5. "Whether attacks are initiated by a conception of breathlessness in a closed room or a stuffy atmosphere, giving rise to the belief that his breathing is. actually embarrassed."

6. "Whether some intimate has had asthma in severe form, and imitation can be shown to have taken place." These criteris are believed by $\mathrm{Dr}$. Gillesple to "make possible understanding of the reason for the cholce of asthma as a special mode of expression of mental unrest, whether the latter takes psychoneurotic form or not."

0. H. Brown (16), represents a group belleving that the greatest cause for the asthmatic attack is a"morbid attention to the act of breathing", which, thereby, is made an active muscular effort instead of a passive one. This non-passive expiration on theory would tie in with the studies of Zeigler and Elliott (22), though they do not mention 1t. This method severely limits the scope of studies as well as the attitude toward an adequate physico-psychotherapeutic regimen. In passing, it might be mentioned that the only treatment recommended by this school of thought is that of breathing exercises designed to habituate a longer inspiration period than the expiration period. There are no statistics given as to cures or emelioration of the condition by this method, although the most optomisftic opinions are given.

One of the finest methods, applicable to children in the main, was tried by Maxwell, Ryerson $(17,18)$, and others under grant for the purpose to the Royal Chest Hospital in 
THE PSYCHOGENIC FACTOR IN ASTHMA

London. Here the patients are taken from their home environment and placed in the controlled confines of a rest home in which every effort was made to make the patients happy and contented. Studies were made with great accuracy over every detall of the child's personality and the parents during their visits were investigated also. Accurate checks were kept of the patients upon their return home. Though scarcely applicable for any but children, no happier or more promising method could be evolved. It was, however, very expensive, with the care of some individuals costing over five hundred dollars. One hundred and fifty patients were so studied. Results will be given later.

Results of investigations into the importance of the psychogenic aspects of bronchial asthma are widely varied, as is to be expected from the wide variety of methods used in the study, and the absence of any absolute standards in judging the etiology of varlous phases of the disease. Another characteristic of the vast numerical majority of the reports is that few investigators have had enough cases to warrant giving percentages of cures, remissions, relapses, etc. The bulk of the material consists of individual case reports; many of these are merely short reviews given without attention to the demonstration of the methods of examination, the criteria used for evaluating the data used, or the use of standard terms for defining mental conditions. Psychological nomenclature used by the general practitioner varies widely from that of the specialist, and sometimes we find the specialists varying as widely among 
THE PSYCHOGENIC FACTOR IN ASTHMA

themselves. In the case reports given below, the attempt will be made to remain as closely as possible to the nomenclature of each investigator followed later a more simple classification of the mental states involved.

In a study of this kind, a large number of case reports are essential, both for the realization of the types of factors involved and for an understanding of the author's analysis. Most of these case histories were very long, and an attempt was made to select only the outstanding features of each case to be presented.

Rackemann (19), cites the following:

Miss F. W., sohool teacher of 48. Most common causes ruled out. Had been treated with vaccines for 7 years. Patient had a chronic cough with asthma through winter months since 32 years of age. Attacks always associated with fatigue and excltement. Rest always cures. Patient became well over a three-year perlod when placed in a position with less rigorous requirements.

Rackemann comments upon the "school teacher type" characterized by an asthenic body type. "Indigestion, fatigue, anxiety and poor general body health are found". The asthmatic attacks are of long standing, persistent and very severe. He considers "positive skin tests not important if found "because most cases yield to psychotherapeutio measures."

Strauss, (4), whose system of grading positive answers to a fixed set of questions was mentioned earlier, (Page 2), gives the following cases:

Widow, aged 66. Asthma progressively worse for 7 years with hay fever, off and on for 
three years. No urticaria, migraine or bronchitis prior to the onset of asthmatic attacks. Happily married 43 years; husband died three months ago. Lost one son in infancy, and one during war over which she has felt great sorrow. By common consent, stopped coitus nine years ago, but things were very difficult with an affectionate husband and a double bed. Kept all feelings and sorrows secret, because she had been reared in a strict puritannical atmosphere. In car felt uneasy and once lost her volice, while talking to the driver to keep him from driving too fast. Sensitive to horses, feathers, pollen, wheat and milk by skin tests.

This patient was seen again in six months and allowed to talk about her difficulties for an hour. Three days later she wrote a letter stating she felt "tremendously relieved" of her attacks as seen on different occasions and exercises. Scored 10 points on questions. Negative on 2,6 and 9 .

Case Man, aged 29, unmarried. He is a chemist's 2 assistant. Has had asthma for nine years and believes it to be from licorice powder, soap, papaine and orris root. His attacks come at monthly intervals. Neurotic family; father nasty tempered, hasty, strict, narrow. Patient has little sex experience. Feels isolated and lonely. Believes in spiritualism. Has nervous breakdowns, suicidal ideas, mother-love, father-hate. Interviewed three times in one month. Patient states that this is by far the longest period he has experienced without an attack. Scored 10 marks on questions. This asthma I believe to be of psychosex equivalent.

Case Unmarried woman, aged 38. Draper's assis3 tant. Asthma for 18 years. First attack with a nervous breakdown after the outbreak of the war, and father's death, although she hated and feared her father, sister and brother. Feels worry brings on attack. Scored 13 points; negative on \#7.

Case Married woman, aged 39 years. First attack 4 occurred ten days before interview took place. Always nervous, especially during her periods; notes depression, biting nails. Had to take care of mother-in-law who died of asthma and sympathized greatly. Score 7 points. 
THE PSYCHOGENIC FACTOR IN ASTHMA

It is to be noted that Dr. Strauss bases none of his conclusions upon definite cures, but upon the accuracy of his system of grading the answers to his set of questions. The etiology of nervousness was not considered. His summary is as follows:

1. "Thirty unselected cases of asthma were examined in the out-patient department with the view of determining absence or presence of "nervous" psychic or emotional factors in the asthma syndrome."

2. "A special ten point scale was adopted for grading."

3. "The Nervous Element was strongly present in sixteen cases, well represented in tine cases and feebly but definttely in one case. Negative in one case. The allergic factor was not taken into account."

$$
\begin{array}{llllll}
\text { N. E. } 3 \text { plus in } & 16 & \text { equals } & 53.3 \% \\
\text { " ". } & 2 \text { plus " } & 9 & \text { " } & 30.0 \% \\
\text { " " } & 1 \text { plus " } & 4 & \text { " } & \frac{13.3 \%}{96.6 \%} \text { Total } \\
\text { " " } & 0 & \text { " } & 1 & \text { " } & 3.3 \%
\end{array}
$$

In Strauss' report we find an exceptional effort to standardize methods of evaluation of the psyche In the production of asthmatic attacks. However he neglects the fact reported by numerous investigators that allergic excesses often produce a hyperexcitability, $(6,9,10,11,12,15,19)$. He has no semblance of a control mechanism, demonstrates no positive cures, and fails to follow up hls cases. Howerer, from the indicated remissions, we may accept some positive evidence 
THE PSYCHOGENIC FACTOR IN ASTHMA

toward the precipitating nature of emotional stimuli in thirty unselected cases presented.

Strauss' own summary both from the cases presented here, and from other investigations are as follows:

1. "In its psychic aspect, asthma may, in certain cases, be complex-determined; i.e. included in the group of conversion hysterias."

2. "A person with the allergic diathesis who is temperamentally a deviant from the conventical norm of his immediate social group, is likely to develop the asthma syndrome."

3. "An asthmatic subject is likely to make his asthma the center of his life; i.e. to develop and cultivate an asthmatic persona (Jung's,44, term). Such a person by the mechanism of what Kretschmer $(20,21)$ calls arbitrary reflex reenforcement can "turn on" his asthma on all possible occasions whenever it suits his unconscious or preconscious purposes."

4. "Allergic subjects who live under conditions of extreme emotional stress and strain are liable to exhibit the asthma syndrome."

5. "Asthma in an allergic subject may be part and parcel of a general anxiety state, the effect, when the anxiety tension is very high, finding an autonomic reflex outlet." 
THE PSYCHOGENIC FACTOR IN ASTHMA

At this point, the findings by Maxwell (17)

may be used here to give a quantitative idea of the

factors involved in 150 patients studied by him:

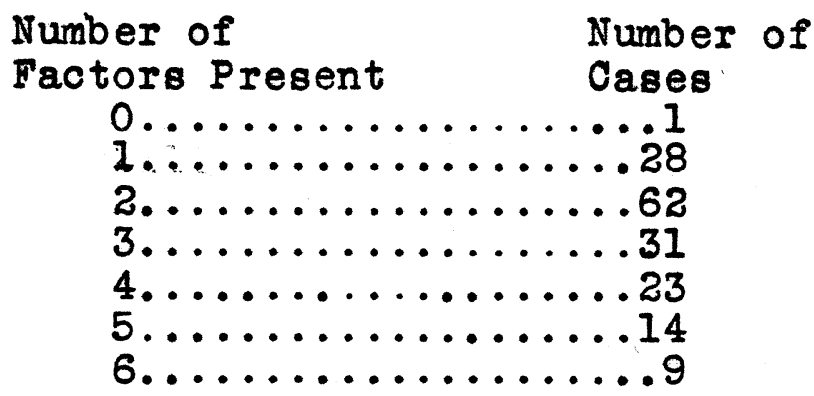

Maxwell found 73 cases allergic, 90 nasal, 75 bronchial, 52 alimentary or endocrine, 74 psychological.

Gillespie (13) of london, cites the following cases which were definitely non-allergic in character:

Case-Young woman left school to teach, but did

1 not like it, and became "too poorly" to continue. Had a job in the Post Office telephone board, but "lost her voice" frequently so had to quit. Disliked or feared new faces, strange surroundings, droughts, closed trains. She "got up and held on" in fast trains. Patient worried "Inwardly" about family finances greatly. Had first attack of asthma while hurrying to mothers' bedside, on fast train. Emotional outbursts seem to start attacks since.

Case-Young woman with a history of chronic cough

2 and bronchitis for five years. Two years ago she was hurrying and had to stop and hold on to post from shortness of breath. Since then has had repeated attacks of asthma, evoked by postman knocking, having Wassermann test, any worry, excitement, smells, meeting people she didn't like, cats and cat fur -- all simple emotional stimuli.

Case-Married woman, aged 37, with history of

3 asthma for twenty years. She is a jolly, over-active, clever person, but over-anxious. She has no morbid fears, never has brooded or been noticeably unsociable. She declared "nothing kept her down long". Attacks brought on by two things; exertion and making her husbands bed, to which hair she was not allergic. However, it was found that they 
were not happy, had lost understanding, and she felt he begrudged her a living. The stimulus here seems psychological association.

Case-Elderly man, with asthmatic attacks provoked 4 by only one kind of tobacco smoke -- that from his brother-in-law's pipe. The two men were at loggerheads with each other, but had to live in the same home.

Case-Woman, aged 49, with asthma for twenty-eight 5 years. Suffered her first attack after her father's death. Her father was very lazy and a chronic alcoholic. Second attack when bearing first baby and subsequent attacks with each pregnancy after the first. Never wanted children, and was sick as well as asthmatic during whole pregnancy.

Case-Man, middle aged. Married; asthma began

6 after birth of second child to which he was violently averse. After he failed professionaliy was forced to accept a small clerical job after which he was pre-occupied with his health, suffered complete loss of ambition, and great pessimism. Improved at once with advice.

Case-Man, middle aged, suffered his first attack

7 while on an unhappy vacation. Attacks recurr when certain topics mentioned in the consulting room. Long since he has used alcohol to drown his unhappiness. Has been a total abstainer since consulting a psychoanalyst. Now a mere tempting thought of liquor gives him asthma.

It will be noted that the cases quoted generally give no evidence of improvement, but are psychologically so clear-cut that the psychogentc element must be accepted a face value. Gillespie's formulation of the factors are advantageously inserted here;

"It is my contention that asthma, in the sense of characteristic attacks, is a peculiar mode of reaction of certain individuals to a variety of stimuli, and that these stimuli may be either of physical or a psychological order. The individual reaction pattern is dependent 
THE PSYCHOGENIC FACTOR IN ASTHMA

on physical conditions which still elude analysis, but which are often undoubtedly purely inherited. If it could be shown that purely psychological stimuli would produce asthmatic attacks, we would have a very valuable field in psychological medicine where the data are so often purely subjective. Asthma attacks are so distinctive, they may be used for example, as color changes in chemistry analysis, I am sure that the study of the asthma patient will be very far wrong if the possible psychological factors are left out of consideration."

Gillesple gives three reasons "why asthma is often associated with psychological unrest:

1. "The stock rating high in the production of asthmatics can also be shown to be high in psychoneurotic manifestations as shown by Addis chart on the inheritance of asthma:

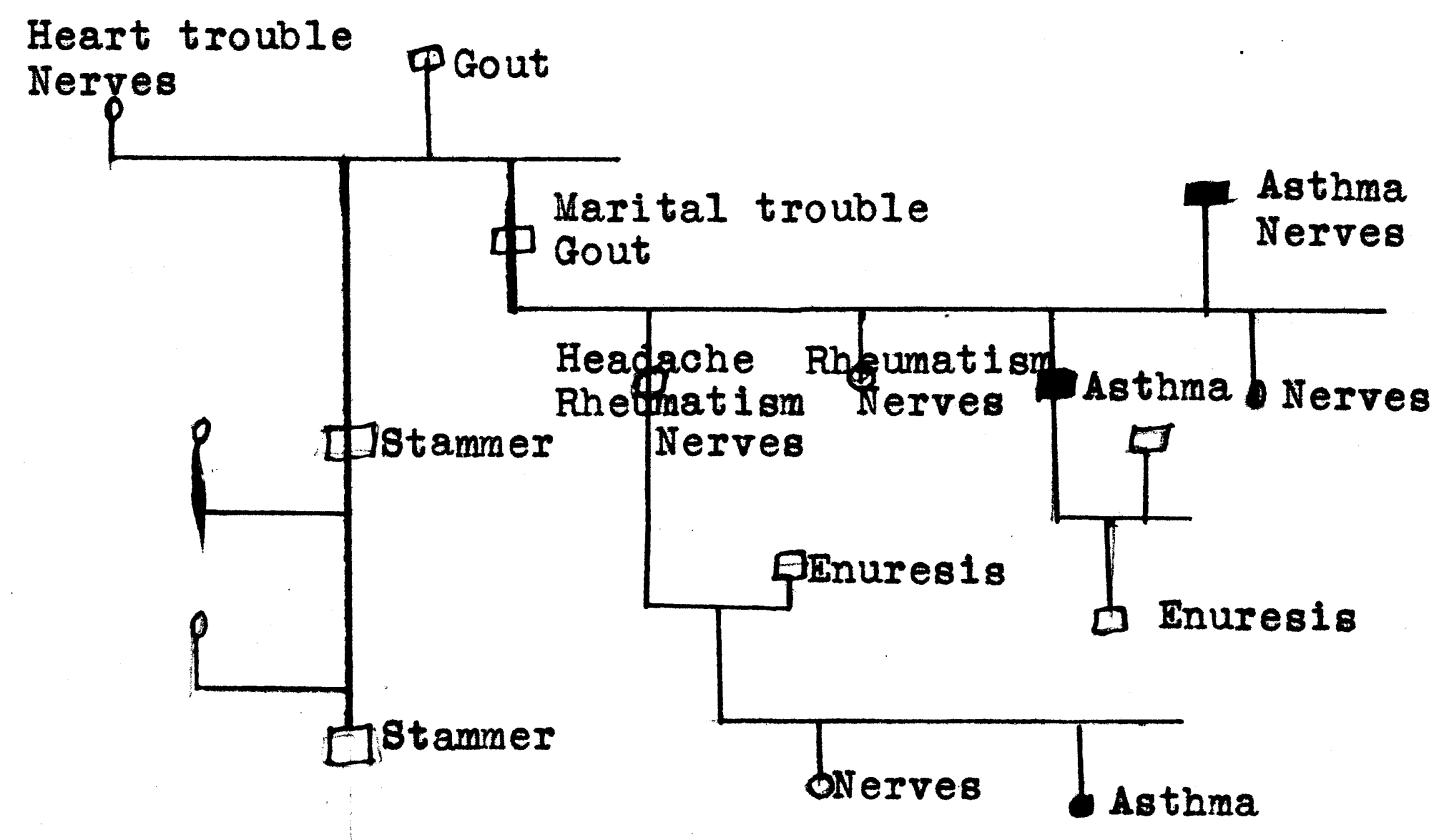


THE PSYCHOGENIC FACTOR IN ASTHMA

2. "The function of breathing is very much subject to emotional influence in everybody. It is a commonplace in literature; catching one's breath in grief or fear, the sigh of sadness, rapid breathing in excitement or anticipation, the expansion of the chest in joy, the choking of anxiety. Objective studies $(22,16)$ have shown the close relationship between emotional stimuli, the state of mind and the respiratory function.

3. "Physiological mechanisms of attack function through a disturbance of the vago-sympathetic "balance". This balance is much affected by emotional states. Everyone knows of Cannon's (23) experiments on dogs showing effect of excitement in producing adrenalin. A much older observation shows that every emotion tends to be propagated like a wave of physiological disturbance through the vagal and sympathetic systems to the viscera. If there are already some disturbances of the vago-sympathetic system, clearly the emotional disturbance will have unusual effects, and asthma may be one of them."

"An idea may become the effective stimulus which elicits the asthmatic response just as much as pollen and horse hair. Not only may psychological factors in the shape of emotions or ideas elicit individual attacks; but also they may act in continuous fashion to produce a state of tension which every now 
THE PSYCHOGENIC FACTOR IN ASTHMA

and then may reach explosion point, and express itself in an asthmatic paroxysm.

"The aspects of psychoneurotic symptoms may be Iisted as follows:

1. As expression of a mental conflict or state of uneasiness.

2. Symbolic of the nature of the conflict; for example, the fear of suffocation remembered from a pillow fight during childhood.

3. Teleologically; as a means of escape or a drive for sympathy.

4. As a conditioned reflex of psychological or physical nature, where effectiveness is due to psychological associations."

Here, in order to complete the train of thought advanced by Gillespie, we may repeat the reasons why asthma is the choice as "a special mode of expression of mental unrest", depending on:

5 1. "Constitution".

2. "On accident of time, for example hurry plus breathlessness, plus mental stress, initiates an attack.

3. "Pre-existing fear of lung disease."

4. "Pre-existing lung disease fixing attention to that organ or creating an organ-inferiority impression of Adlerian type".

As a summary of mental causes, Gillespie reports the following:

1. "Cumulation of anxiety in a psychoneurotic 


\section{THE PSYCHOGENIC FACTOR IN ASTHMA}

personality.

2. "Equipotent mental forces with physical

stimuli in precipitating individual attacks."

3. "As a condition of response to a physical

stimulus with psychological association."

4. "Replaced by anxiety symptoms."

5. "Replaced by elation or depression in a manic-depressive or a schizophrenic psychosis."

6. "Expressing conflicts, for example, impulse and conscience, etc."

7. "As a protest against an unwelcome situation."

8. "As a means of escape."

9. "Improvement or removal of the symptoms by suggestion, hypnotic or otherwise." Incidentally, Gillespie belleves that "a certain proportion of the so-called "visceral neuroses", eczema, prurigo, urticaria, migraine and epilepsy bear much the same relationship to mental stimuli." Clarkson's (4-Case \#4) demonstration of the effect of hypnotism upon skin testing may be of significance here.

At Abbasia Mental Hospital in Cairo, Egypt, M. K. el Kholy (24), reports on the first cases of asthma he had ever seen:

Case-Married youth, aged 27 years with asthma of 1 severe nature for eighteen months, with onset one-half hour after arising in the morning. Treated over a years' time by three prominent doctors, during which he frequently had attacks about 2 A.M. with a feeling of suffocation, dyspnea, wheezing in chest, cough, expectoration, sweating and coryza. Mental examination showed:

1. Severe fear of harsh father 
THE PSYCHOGENIC FAOTOR IN ASTHMA

who is dead.

2. Vague fears of devils since childhood-suggestions by his nurse.

3. Afraid of dark; always left light on; believed saw father several times with his red cloak on.

4. Two weeks before first attack suffered great shame when a neighbor woman discovered a terrible ghost to be a pile of soiled clothing.

5. Dreams of fear for children or his own safety; awakens in a state of horror.

The patient states that his anxious expectations on awakening are relieved by an asthmatic attack. States that his fears and anxieties were much less since onset of his illness.

Patient was treated with explanation, persuasion and re-education. In three weeks, patient gave up all medication, lost his fear, and has been of almost normal constitution for over a year.

Dr. el Kholy states his belief that "fear

alone does not produce a phobia; the incident causing it must be such as to evoke self-approach, shame or a sense of guilt. In the present case cowardice shown before his wife and neighbors supplemented the fear " to produce a summation of excitation.

Case-Nurse, aged 17, working in a mental hospital. 2 Nine-year history of typical attacks of asthma suffered a week or two apart, lasting from one to four days. Three months prior to onset nine years ago, she was cornered and bitten by a large dog in a closed hallway. She states she lost consclousness and on recovering felt an acute sense of suffocation. Confined to bed for three months with disturbed sleep, fear of anyone entering room, terrorizing dreams accompanied by a sense of suffocation. After leaving bed she began to get typlcal attacks of asthma. Subsequent attacks came with any unpleasant surprise, for example, caring for a violent patient, another person standing behind her, etc. She was very ashamed of her fears, but since childhood had been 
THE PSYCHOGENIC FACTOR IN ASTHMA

reared to believe in vague, monstrous, fearful beings menacing her.

Treatments given as in Case 1. Complete freedom from subsequent attacks for over a year.

Dr. Kholy further states: "These represent my whole experience with the asthma syndrome, and the similarity of causation is striking. Both patients were of neurotic constitution, and gave a history of fear or anxiety. Both showed their symptoms after a situation of great fear followed by shame which produced an acute internal conflict which was solved by the onset of an acute bodily illness; this largely substituting itself for the attacks of anxiety. Treatment of a mental type gave complete relief. I believe the question of a tendency toward asthma rather than some other disease is in question". Wittkower and Petow (25), in an abstract, reported by Sprunt (14), report the following cases:

Case-Child of 10 years saw mother very 111 with

1. pulmonary disease and dyspnea, and a $f e w$ days later developed asthma herself.

Case-Patient; a middle aged woman, could find re-

2. Iief from her attacks by going outside into the yard. Finally she could merely look out of a window and avert an attack.

Case-Patient, a middle aged man suffered asthma

3. from smoking tobacco, to which he was proved allergic. Following psychotherapy alone, the patient lost his asthma. Skin test reaction remained positive.

The authors conclude that "allergic factors remain unchanged after psychotherapy, hence cannot be held completely responsible for the asthmatic reaction." 
THE PSYCHOGENIC FACTOR IN ASTHMA

Witts (26), cites several cases proving

his theory that "there is a general tendency of asthmatics to respond to any kind of treatment, providing treatment is faithfully and seriously administered". In these cases which were all allergics, he used a treatment of $I$. V. saline instead of vaccines, in a faithful series of treatments, and found that "the patients still improved, or complained that they were much worse following the saline injections."

Norman (27) from Houckgeest (28), Kirschbaum, (29) Hofner (30), and Gundrum (31), / andhers $(6,14,12,62$, to 64,67$)$ submitted reports which point very definitely to the conclusion that there are cases of asthma which are alternate syndromes to various psychoses. They noted that patients with alcoholic, manic-depressive, and "schizophrenic" psychoses as well as some with undefined mental disturbances slipped Into the asthmatic state on recovery of rationality. Houckgeest reported one case of some type of psychosis during which the asthma subsided but did not disappear entirely. With the excepof the latter patient, all cases reported were described as possessing the alternate syndromes well delineated from each other. We may say that the asthma syndrome coincided with the degree of rationality, and that these findings congute constitute almost direct evidence of the "substitution" character of some asthmas. In none of these, however, is any allergic tendency mentioned, which lack, in the light of findings presented by Olarkson (6)-(to be given below), and others, 
$(9,10,11,12,15,19,32,33,78)$, casts some doubt as to

the completeness of the analysis of the above citations.

Hansen(5), reports the following case which

seems to present the clearest picture of a definite

psychic influence in the production of asthmatic spasm:

Case-Subject: "Allaged 48, states asthma started at the age of 11 and lasted until 14 . Onset

and duration of first series of attacks coincided with a period of extreme worry over "cribbing" she had done in school to remain at the head of the class. The asthma ceased at age 14 after she had confifded in and been reassured by "B", an elderly man whom she loved and respected. No asthma for five years. Next series of attacks came during an infatuation with a polished "rake" whom she did not love. After three years of attacks, she left the man and had a complete remission for four years. Married unsatisfactorily, and had third series of attacks after again meeting the rake with whom she had had relations prior to her marriage. These attacks lasted for seven years until the war came to occupy her time. Asthma again started when "B" died and were continuous until I interviewed her. Since being under my care with psychotherapy she has used no medicines and has had a complete remission of symptoms. Skin tests showed her to be allergic to feathers and house dust, but no specific treatment had been of success. The history was gotten with no leading questions and was absolutely voluntary.

Hansen notes the unusual findings in allergy as follows:

1. "The frequency of allergic diseases depends largely on the amount and concentration of the absorbed allergen, which are insignificantly strong in. general clinical importance, so the number of cases of affective allergy is relatively small."

2. "Patients can, at times, stand the presence of the specific allergen with no reaction. The hypothesis of the temporary immunity due to illness can not satifactorily explain the haphazard rise and fall of many allergic 


\section{THE PSYCHOGENIC FACTOR IN ASTEMA}

symptoms.

3. "Other factors affect the absorption and effectiveness of allergic attacks. Here we find both endogenous (Infectious,periodicities, etc.) and exogenous factors (climate, gases, etc.). However these factors are usually not found in the usual patient to any important degree.

4. "Observed dependence of allergic forms of reaction upon psychic influences:

(a) The sudden abortion or aggravation of an attack is more easily explained if we know the patient to be of a"nervous" constitution.

(b) Hypnotism may temporarily or permanently cure.

(c) Hypnotism alters affect of allergens. Hypnosis of three cases and then exposing them to massive doses of their specific allergens precipitates no attack although the skin test reactions are unaffected." Hansen concludes that "psychotherapy removes the mental factor in an attack, and diminished the irritability of the vegetative nervous system, but does not affect the hypersensitiveness". He admits "this form of treatment needs careful evaluation and should be considered symptomatic" and not specific. 
THE PSYCHOGENIC FACTOR IN ASTHMA

Zeigler and Elliot's (22) experiments with

the pneumograph and Electrocardiograph on six nervous cases and three allergic cases showed the disturbing thoughts to be definitly responsible in the nervous cases, for a marked lengthening of the expiratory phase and a slight pulse rate increase occurred. There was no effect observed in the three allergic cases. The authors advance the following conclusions:

1. "Emotions of psychological stimuli seem to induce asthmatic attacks in a limited number of patients without a history of sensitivity.

2. "In six neurotic individuals, definite respiratory changes were observed with emotional stimuli; no changes in the allergic, non-nervous cases.

In the absence of sensitivity, emotional stimuli should help explain the disease in a limited number of patients."

An analysis of the forgoing would show that the method shows great promise, but is not extensive enough, nor does it have sufficient background of research to strengthen the fundamental postulates involved.

Romer(34) is one of the group reporting cures without analysis of the factors involved, but cites these findings:

Case- Woman, middie aged, had asthma for 16 years. 1. With psychotherapeutic treatment all symptoms subsided, the eosinophilia went down from $24 \%$ to $4 \%$ without relapse.

Case- Patient under constant treatment with potassium

2. sodide, asthmaolysin, af enile intravenousl, morphine, nasal operations, $\mathrm{X}$-ray irradiation, 
to the hilus and many others. After one week of psychotherapy, the patient became free from symptoms and has had no relapse.

Oberndorff (35) cites the only fatal case reported: (See also 48 , to 60 )

Case-Woman, aged 30 with depressions, homosexual tendencies, lack of proper sex satisfaction. Positive sk in reactions to corn, cabbage, chicken feathers, dog and cat hair. Onset of asthma after sex difficulties with her husband. No relief from avoidance of allergens. Patient almost moribund when I removed all medication, gave sterile water injections. Patient finally recovered and was free of symptoms under psychotherapy. After a years' time, the stress and strain of her daily life became too great. She refused medical services, took massive doses of adrenalin for months. Finally died from bronchopneumonia. It should be noted that, during the year passed without symptoms, constant contact with all of her allergens falled to produce an attack.

Clarkson (6) who has spent a' great deal of time upon the subject, and has formulated one of the most comprehensive analyses of 300 cases is a psychoanalyst, hence many of his explanations of psychological situations will seem too closely drawn for many investigators. The importance of his analysis cannot, however, be over-estimated:

1. "Intensification of emotion occurs as an integral part of autonomic dis-harmony produced both by allergic or biochemical factors." (See also 77)." 2. "In some patients, the psychological phenomena occurring in asthmatic states are entirely dependent on a disordered biochemistry."

3. "If the latter factor is not treated adequately, there tends to be a perpetuation of intense 
THE PSYCHOGENIC FACTOR IN ASTHMA

emotional life, maximal when the allergic imbalance is augmented. A habituation reflex is established, the primary nuclei of which are based upon fear."

4. "According to the temper of the child, this reflex may be used as a "retreat into illness", or a psychopathic way of escape from reality."

5. "The sense of organ inferiority can energize emotion into a physical expression."

6. "Frequent repetition of the original

stimulus leads to diffuse psychopathological derivatives which permeate and color the life of an individual, and may at any time cause an attack."

7. "This latter factor especially explains the freakishness of asthma."

8. "Where psychological factors predominate, treatment is prolonged and uncertain."

9. "In a small but definite number of cases, asthma is the expression of a definite psychosis."

Case- An only child, aged 7, had suffered from 1. allergic bronchitis since infancy. Father a chronic dyspeptic; mother had migraine. After birth, mother seemed to lose a guiding motive in life. Migraine attacks became frequent. Suggestion of a holiday or other amusement invariably initiated an attack. Several times a week, the child would see her mother incapacitated by a headache. Later, the mother "over-protected" the child who developed a capricious appetite, stayed in bed in a dark room and wept copiously. Gotten up, patient spoke like a child of 2 , and walked with a corresponding gait. She was recapitulating the infantile regression seen in her mother in modified form. 
THE PSYCHOGENIC FACTOR IN ASTHMA

Case- Boy, 9, developed asthma at age of 5 . He 2. is the eldest of four children. Attacks occurred at about monthly intervals when I was called, because he was hopelessly unmanageable. Patient attempted to set the house on fire three times. He shows sadistic cruelty with other children, and bites and scratches his governess. On my arrival he hid, but was carried into the house yelling and biting. Examination was not possible; I could only talk calmly to him. On leaving, he said he would drop a big stone from the roof on my head when. I came back, and subjected me to a torrent of abuse. Three months later, freed from allergic thralldom, this patient became a quiet, well-mannered boy. He has suffered no asthma since.

The author explains "when there is an overstepping of allergic tolerance and asthma ensues, a further disturbance of the pre-existing tension states takes place. The most important clinical feature is lack of any psychic "buffering". Anxious parents frequently make matters worse. The patients judgment is impaired, the turmoil of anticipating diseases becomes stronger, and, by an association network rendered momentarily freer, extends the range of fear memories. Thus it is that so frequently we find bouts of rage and uncontrolled wildness alternating with terror, and the assumption of the characteristic spastic posture of hunching forward with a haggard face. Statistical thinking is replaced by a primitive "magical" thinking, whereby effect is detached from the ego and externalized." "Every word or action in the non-ego is invested with potential danger. The visit of the doctor and the view of the apparatus are identified with the fear they might be expeoted to evoke! "What 
is this for.... what will it do.... will it hurt me.... I won't have it.... I don't like it....I'll run away!"

$$
\begin{aligned}
& \text { Case- (Same type as \#2) } \\
& \text { 3. Boy aged 10 with a history of allergic } \\
& \text { bronchitis. Urticaria and eczema supervened } \\
& \text { and eventually asthma occurred. Patient was } \\
& \text { extremely emaciated, nervous and emotionally } \\
& \text { unstable with the same type of psychological } \\
& \text { reactions as in Case } 2 \text {. His method of avold- } \\
& \text { ing a potential danger was to wait behind a } \\
& \text { hedge with an air gun for my arrival. After } \\
& \text { four months treatment by eliminating diets, } \\
& \text { his asthma had ceased, and he was able to } \\
& \text { live as happy boy. }
\end{aligned}
$$

(One might point out here that statement by Witt (26) that any treatment carefully given and religiously adhered to, tends to cure many asthmas).

Case-Asthmatic girl of 18 showed severe skin 4. reaction to intradermal test for egg white sensitization. A wheal one centimeter was produced at the site. A repeat test next day under hypnosis was made with the suggestion that no reaction would occur, frequently repeated for a half hour. No wheal occurred and no erythyma. The next day, the test was repeated in the patient's normal state and the original wheal was obtained. This will show how psychological factors can exalt or lower allergic thresholds.

"Should this paroxysmal overstepping of the allergio threshold continue unchecked, a stage is reached where a great modification of personality temporarily ensues. The psychic disorders dominate the cerebration for a time and arouse anomalous conduct disorders. Clinical study shows that, in the asthmatic, the normal adjustment mechanism by the control of higher centers is out of order"

Case- A medical student aged 19, states, "several 5. days prior to attack, I have a craving for unusual or highly spiced foods. I tend to smoke much, and lose my power of concentration. 
I lose the train of thought, and a few minutes later mix the conclusions in a new rush of ideas which become more and more tinged with emotions. My voice becomes high pitched, almost a scream. I seize upon irrational thoughts and try to put them over with unjustifiable conviction. Increased irritability makes me dwell on ideas of resentment. Fancied slights of friends are magnified and distorted. I remember my enemios with great rage. Mentally I torture them with sadistic glee as though a dictator. Helplessly I feel myself an anarchistic enemy of society. These feeling are very real indeed, to me at the time, and yet when the attack is over, and I think of them, I realize how foolish they have been."

Clarkson further states: "All evidence points to the fact that allergic asthma is primarily responsible for the onset of juvenile asthma, and the psychic factor is either mobilized or intensified by allergic states. This conclusion applies only to the early stages of the syndrome. When, however, the condition has continued for some time, diffuse psychdogical reactions centering around the organ inferiority emptasize the pre-existing emotional fear.

"The potential asthmatic child enters the world with a somatic and a psychic handicap. Not merely may he be victim of an active or passive sensitivity from his mother, but of a chromosomal inheritance from the father. He is born into a keenly competitve world, and early environmental influences begin to impinge upon a highly sensitive sensorium with invidious insistance. Frequently, it is the eldest or the only child, and domestic pampering by parents, often themselves the victims of allergic imbalance with 
THE PSYCHOGENIC FACTOR IN ASTHMA

with its concomittant psychic reactions, directs attention to physical insecurity. Moreover, every other illness is a source of anxiety, since by increasing the sense of constitutional weakness, it tends progressively to undermine confidence."

"In asthma, frequently autonomic hyperexcitability initiated by allergy, is an ideal soil for the formation of fear complexes (36). The direction of attention to the condition lends it emphasis. Physical defects confer on the victim an aura of invalidism, and the psychopathological thinking of his parents surround him with an almost pathological limelight. "In any situation that is a potential danger, fear is present if attention is given to its dangerous aspects."(Rivers) Fortunately, the children have some compensation because they are usually above standard mentally, excel in the classroom, read a great deal and mature very early.

Once the experience of bronchospasm is sufflciently repeated, there can be no doubt that it acquires all the character of a conditioned reflex, and at this stage, the memory of previous analagous stimuli is sufficient cause for its persistence.

Once established as a conditioned reflex, the potential catalysts, both somatic and psychic become numbrous indeed. On the somatic side; the activity of almost every organ under the control of the vegetative nerrous system can eventually be the trigger of vagosympathetic imbalance. Thus a loaded rectum, a swollen 
THE PSYCHOGENIC FACTOR IN ASTHMA

mid-turbinate, a distended stomach may initiate a spasm. Correspondingly, the diffuse ramifacations of the psyche, centralized around the primary emotional nucleus of fear may, at any point, lead to an attack. This is of great importance from a prognostic standpoint. In some long-standing cases, the ideas clustered around asthma may color the whole outlook on life. In such cases, future security is to be found only in analysis and sublimation.

"Emotional shocks that are final cannot be forgotten. Many associations recall them (20). Every remembrance may be the occasion for the renewal of the original stimulus through a sensitized set of responsive neurones. Associated agencies may also touch the "agitating spot". Anything that will influence a sense organ is convertible into an affective stimulus. This explains why artificial flowers may provoke an attack in a sensitized subject.

Case- A brilliant girl, aged 20 , suffered from 6 . asthma from the age of 2 years. No allergic findings. Five months of ordinary psychoanalysis with no effect. Hypnoanalysis revealed that fears went back to age of two years when she was assaulted by a negro who "would cut her tongue out" if she told. The mere revealing of the cause did not cure this patient because early terror had permeated every sphere of psychic activity. Gradually she gained courage to kill this man in her dreams. When her fear ended, her asthma vanished.

Ultimately dependent upon the conditioned reflex, there emerge three other characteristics which we may find in the course of the syndrome: 
THE PSYCHOGENIC FACTOR IN ASTHMA

1. Purposive stimulation

2. Hysterical habituation

3. Voluntary reinforcement

"This chain is most frequently determined by parental reaction, in my opinion. The more intense the emotional lives of the parents, the more easily will the child energize the reflex pathways with purposive intent:

Case- Boy aged 11 years with the history of
7. eczema and cyclical vomiting with asthma
for three years; sensitized to egg, milk
and fish. After desensitization, he ac-
quired a new poise in life, took new
interest in hobbies and recreation, and
became stronger physically. If, however,
he received a reprimand or his wishes
were thwarted in any way, a change came
over him. The shoulders hunched, the
pupils dilated, and he threw himself
into an attitude of "expectant defense".

"A stage may be reached when attacks no longer depend on allergic catalysts. Emotional factors, alone may be the "trigger", employed sometimes as an explosive demand for sympathy, or as a mode of escape from unpleasant situations. Great complexity of behavior results. It is important to stress early treatment to avoid the habituation reflex. Every time the nerve stimuli travels certain paths, they facilitate passage of later like-impulses:

Case- Boy, aged 12. Had asthma for eight years. 8. Mother died six weeks after his birth. He was brought up in the charge of a devoted "nanny" for whom he cherished deep affection. Sent to Switzerland, he grew and became well. Subsequently he suffered one of his most severe attacks after his father told him he was going to be married again. The latent emotional factor had not become sublimated. 
THE PSYCHOGENIC FACTOR IN ASTHMA

"Seldom without audience, frequently in early chronic cases, and greatest in psychotics do we see an arbitrary reflex reinforcement of bronchospasm. It is entirely psychological and magnified proportionately to that factor. Machinery of expression is through the accessory muscles of respiration.

"In the presence of bronchospasm, the patient emphasizes the distressing nature of his condition by contraction of the bulging ale nasi, bulging of the sternomastoids, the shoulder tips thrust forward and curving the thoracic spine markedly into a hunch. The chest wall is oppressed on a rigid diaphrahm with compelling insistence. The inspiratory effort is correspondingly labored with almost masochistic intent:

$$
\begin{aligned}
& \text { Case- Youth of } 17 \text { years developed asthma after } \\
& \text { 9. leaving school at age of 15. Father is } \\
& \text { asthmatic; both parents considered him } \\
& \text { "queer". Patient procured and lost sev- } \\
& \text { eral jobs in succession, gradualiy be- } \\
& \text { came confined to bed, and retired from } \\
& \text { friendly contacts. One day I found him } \\
& \text { asleep, breathing easily; on waking, he } \\
& \text { assumed the condition above described } \\
& \text { until his lips were cyanosed and adventitious } \\
& \text { sounds filled his chest. Sharply repri- } \\
& \text { manded, he recovered at once. } \\
& \text { " Here we should discuss psychotic dissocia- }
\end{aligned}
$$
tion. In two per-cent of chronic cases, the motivation proceeds from very old and involved complexes. Rarely allergic manifestations are found in these cases. Being autistic in temperament, and well-nigh divorced from realism with an intense ego-localization, they live at the level of mid-brain philosophy. The deep psychic 
THE PSYCHOGENIC FACTOR IN ASTHMA

values of the "retreat into illness" cannot be surrendered to any form of sublimation. These patients are not hypnotizable, and the asthma appears to be of purely endopsychic growth. Narco-analysis with sodium evipan, diet therapy and insulin treatment are ineffective. No therapy is found to be effective:

Case- Girl aged 18 years. Epileptic mother. 10. Has had asthma for twelve years. She was bright in school until 10 years of age, then became "queer". She bellieved a gypsy had cast a spell over her and she would never recover. Eventually she was institutionalized. No allergy found. No success with any therapy.

"Most attacks take place in the early morning, hence the dream-life should be investigated. During sleep the vagus is active and exhibits a tendency for easier reflex activity. Bray (37) suggests that since a child may sleep through a "wheezy" turn, the psychological factor cannot play any part in its production, however:
Case- Girl aged 5 years with asthma for three 11. months. Developed attack following re- primand at school. This attack lasted all day and continued during the night. I called, and heard the wheezing from the next room. Going quietly to the child, I whispered the suggestion that she would not awake, that her breathing was becoming quiet, and that she would pass into a normal restful sleep. Similar suggestions were repeated at minute in- tervals. The labored respirations began to fade away, the breathing began to less audible and within ten minutes, the spasm had completely abated and the child was sleeping peacefully.

"The relation of dreams to nocturnal asthma affords much valuable information in this respect. Many Psychologists believe that many mechanisms may be 
THE PSYCHOGENIC FACTOR IN ASTHMA

manifested as a purely endopsychic autonomy, while others subscribe to the view that their impetus and direction are initiated by psychogenic disturbance. From my investigations, I believe that in asthma both conditions may apply at different times. Thus hypnoanalysis showed that in the early stages of treatment, somatic disturbance usually stimulated the dream pattern. In later stages, the dream fiction was more frequently endopsychic. The reason for this fact may depend upon the progressive stabilization of the vago-sympathetic balance. Thus McDowell concludes that when the body is at rest, vagal activity is maximal. Pottinger asserts that potassium, and to a lesser extent sodium are associated with vagus activity, whereas calcium is associated with sympathetic stimulation. We may say then, that nocturnal attacks fall into three main groups:

1. Purely endopsychic origin.

2. Effective unrest (expectation of attack before going to bed.)

3. Arousal of the dream pattern by somatic changes:

Case- Dream started at 2:15 A.M. "I was in a long, 12. dark room with small high windows and cobwebs everywhere. The door was locked on the outside. A man came from behind the piano in the corner, put his hands around my throat and began to choke me. I struggled to escape. I remembered I had a knife in my pocket. I clutched it, wriggled around and stabbed him. He fell to the floor, dying. I rushed to the door, beat on 1 t and shouted. Everything seemed to go tight and taut. I couldn't 
get out. I awoke with a case of asthma." Questioned as to somatic sensations, patient states that prior to her dream she was lying comfortably on her right side. There was no visceral disturbance and no cough. I interpret this, having respect to all the factors of the case, to be purely an endopsychic stimulus.

Case- "I went to bed worried about the death of 13. my sister, and couldn't go to sleep for a long time. I fell asleep at midnight. At 1:30 A. M. I was conscious that my stomach seemed swollen. I coughed twice and turned upon my left side to lie on my back. I remembered that coughing often brought on an attack. I began to dream I was alone in an empty house. Plaster was falling from the walls. The roof began to sink in. I tried to escape, but couldn't find a way out. I heard my heart thumping louder and louder. Breathing was difficult. The dust made me caough more and more. I was being suffocated, and I awoke with asthma."

The "occasion apparatus" continues to function automatically once it is set in motion, provided an adequate stimulus is applied. Many nocturnal attacks suggest that affective unrest on going to bed is apparently capable of determing the onset of an attack. Adler: "It is not remarkable that a dream fiction spurs furthur this effort of anticipation in a form to cause fear."

Case- "I was aware that I was wheezing at two14. o'clock. I began to dream that I was bathing in the sea. I felt myself sinking, and began to struggle. My breathing was difficult, and I felt myself choking. I attempted to fight to the surface, and awoke, sitting up in bed with asthma."

Undue departures from normal values place the asthmatic in a potentially spastic state. It is so frequently forgotten that cerebral tissue, whereby the psyche is made manifest, must correspondingly share in any biochemical disturbance. It is therefore a diagnostic 


\section{THE PSYCHOGENIC FACTOR IN ASTHMA}

fallacy to look, in the early stages of treatment except rarely, for a purely insulated endopsychic interpretation. Simon states that: "if, during sleep, an organic apparatus is in a state of activity, stimulus or disturbance, the dreams will present ideas which correspond with the nature of the organic function carried out by that apparatus!"

"In Asthma, these stimuli are wont to travel along certain established paths. Reaching the autonomic stations in the mid-brain, they are freed from the inhibitory influence of the corticothalmic fibres. A great deal more work must be done before we have positive evidence that the disinhibitory action of the higher centers in the asthmatic is dependent upon a lack of synaptic buffering due to a calcium deficiency, but this is feasible. The dreams associated with asthma are almost "pre-selected". Whatever be the artistic imagery woven into them, they frequently return to the 'agitating spoti". (For further references on psychological references used here, see \#23 and \#38 to \#47.)

W. L. Brown (8), although he cites no cases, may be quoted here. He gives a "comprehensive formula" for asthma:

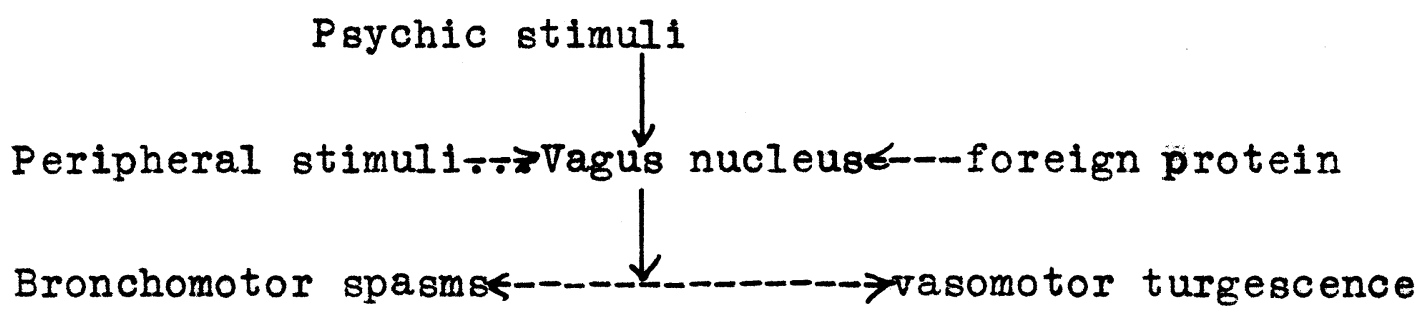


THE PSYCHOGENIC FACTOR IN ASTHMA

He states that "cures by the injection of distilled water demonstrate the presence of psychic stimuli. Conflicts elicit many states, one of them being asthma. Others are phobia, obsession, paralysis, tic, contracture and anaesthesia. Vagal spasm is typical of that exaggerated response so typical of pathological states. The undue irritability of the vagus center sets up such a strong efferent impulse that it is not confined to the vasomotor channels but overflows along the bronchomotor fibres. Endocrines, frequently sway toward vagotonia. We must not overlook however, relief of nervous disorders by allergic, and other treatments". This latter statement is also concurred with by the majority of authors: (see especially Freeman $(9,10)$ Clarkson (6) and Rackemann ( 1 ) and Feinberg (67).

Concluding the reports may be mentioned the results obtained in the rest home research on 150 unselected cases by Maxwell (17) and others (18). It was found that those patients with asthma on an allergic basis alone, showed little improvement with systematic psychotherapy. Those combining nervous conditions with allergy or only the former, noted a marked emelioration or complete cure. The most important psychological factor found amoung this group of children was maternal in origin with elther neglect or over-protection as a cause.

There are several reports in German literature of interest which are not included in this paper, but 


\section{THE PSYCHOGENIC FACTOR IN ASTHMA}

will be of supplementary value (68 to 76 ).

One comes to the conclusion that all investi gators who have written on the subject of asthma and been quoted here, are agreed upon the fact that "nervous" or "neurotic" or "psychotic" or "mental" factors may be the independent causative agents in some cases of asthma. However, there is marked disagreement as to how large a percentage of cases for which this statement holds true. In 1882 salter believed $4 \%$, Rackemann assigns $2 \%$, some German writers believe a much larger percent is traceable to the pure factor of psychogenesis of asthmatic attacks. Most writers do not commit themselves to stating any definite figures.

Some investigators/either all or some of the nervous causes of asthma under the psychoneuroses (Gillespie (13), M. K. el Kholy (24), Dejernie and Gauckler (81), Hofbauer (32), Schulze (55), Moos (56) and schneider (59). It is probable that they consider the especial instability of the autonomic nervous system in this syndrome as the psychotic portion.

In the opinion of a great many of the investigators, the important question is:

1. Whether allergic states produce the observed emotional factors in so many allergic asthmatics, or

2. Whether the emotionsl state frequently acts a priori in producing an attach in an allergic individual. Some investigators believe both conditions are possible in different individuals. Situation \#I is believed to 
be true by:

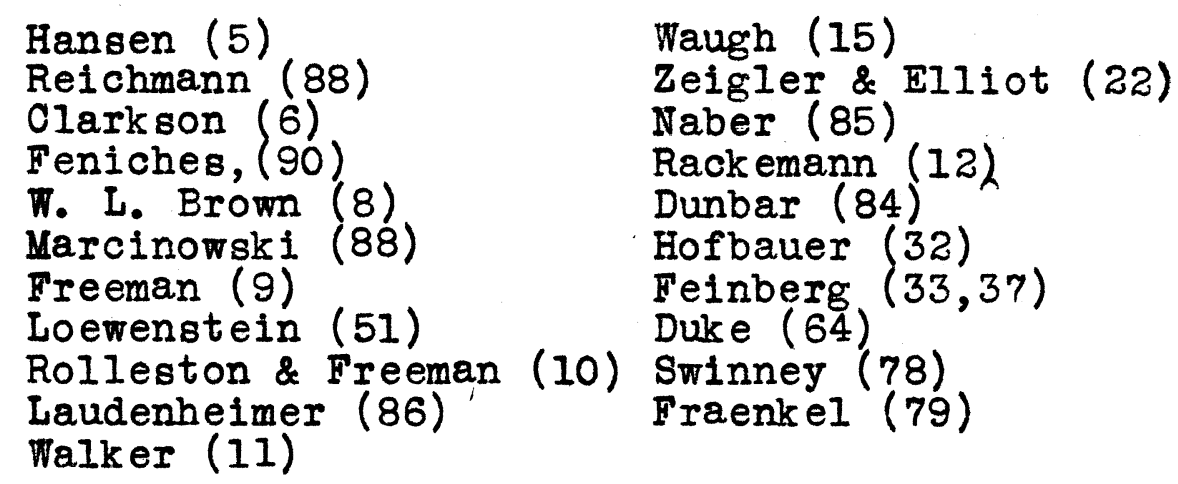

Situation \#2 is believed to be true by:

$\begin{array}{ll}\text { Strauss }(4,7) & \text { Feinberg (33) } \\ \text { Hansen (5) } & \text { Romer (34) } \\ \text { Clarkson (6) } & \text { Hofbauer (32) } \\ \text { W. I. Brown (8) } & \text { Zeigler \& E11iot (22) } \\ \text { Rackemann (12,19) } & \text { Oberndorff (35) } \\ \text { Gillespie (13) } & \text { Wittkower \& Petow (25) } \\ \text { Waugh (15) } & \text { Staekelin (48) } \\ \text { W. K. el Kholy (24) } & \text { Oppenheim (75) } \\ \text { Witts (26) } & \text { Swinney (78) }\end{array}$

Since both lists contain many of the best authorities on the subject, and since the question is one of objective interpretation rather than one governed by precision methods, one must infer that both interpretations are correct.

The observation of the alternation of a rational mental state in which asthma is noted with manic-depressive, schizophrenic or alcoholic psychoses is one of great interpretive interest. This phenomenon has been observed by Gillespie (13), Houckgeest (28), Kirschbaum (29), Hofner (30), Gundrum (31), Clarkson (6) Strauss (4), Jellife and White (62), Rackemann, (12), Jones (63), Duke (64), Feinberg (67), Reichmann (88), Oberndorff (35). Most of them believe that his phenomenon constitutes a proof of the part played by the higher centers of the nervous system in the causative syndrome. 
THE PSYCHOGENIC FACTOR IN ASTHMA

In other words, in the rational state combined with stress and strain, asthma appears as a substitution for a more rational method of meeting those stresses. In the psychotic state, the demand for such a substitute is lacking.

The experience of watching an asthmatic recover under pure psychotherapy has been shared by all investigators in the field. Speabing generally, psychotherapy is an effort to influence in the right direction the attitude of the patient -- to influence his attitude toward himself; toward his mental and physical processes; towards his environment. It is an effort to teach him to understand himself; his illness and the cause or causes of his illness, whether this cause or these causes lie in his body, in his environment or in the superficial or deeper layers of his mental life. The indirect suggestion which flows from the intangtble and imponderable rapport existing between patient and physician is of considerable therapeutic value. Adolf Meyer (93), has evolved the procedures involved as follows:

1. "Establishment of rapport between the physician and the patient.

2. "Aeration or ventilation of the conflict material presented by the patient may be carried out by means of Freudian "catharsis", by direct interviews, by means of discovering and probing from outside sources, by hypnosis or by any other method.

3. Desensitization is the procedure wherein the patient is required to face frankly the traumatic 


\section{THE PSYCHOGENIC FACTOR IN ASTHMA}

and unpleasant experiences of his past. 4. Re-education is carried out in connection with all the above procedures. It is essentially the development of clear insight on the part of the patient into the mechanism of his illness, the establishment of new habits of response and the formulation by him of an adequate industrial, social, recreational and activity program to ensure future stabilization.

5. In addition to the above, it is often advisable to desensitize the patient's family to his illness, and re-educate them into new habits of response toward the patient.

6. All contributing physical factors are corrected as far as possible."

The procedure outlined above is that used by the majority of the investigators, for even the psychonanalysts usually lack the months required for psychoanalytic "catharsis". The conclusions reached are approximately the same whatever the system employed, although the Freudian school tends to develop a terminology fitted to their exhaustive inquiries into the minutiae of psychological mechanisms.

\section{- SUMMARY -}

It will be apparent that most investigators here mentioned believe that there are mental variations of great strength involved in the production of attacks in asthmatic individuals. The onset of the original attack may be produced by either somatic or psychic excitants, or a combination of the two forces. Many 
THE PSYCHOGENIC FACTOR IN ASTHMA

men feel that one of the strongest proofs for cerebral involvement in the causation of attacks lies in the correlation of rationality and the presence of asthma when an alternation is observed in the patient of functional psychoses with periods of rationality. That the temporary or permanent relief following psychotherapy is to be regarded as an indication of the strength of the psychogenic factor. These cures are to be regarded as symptomatic only. It will be recognized that there are great variations, as would be expected, between students of the subject as to methods of analysis, strength of controls used, type of psychotherapy and evaluation of the various phases of the course of the disease, treatment and recovery. These differences will not prevent a simple logical set of conclusions from being reached. CONCLUSIONS

1. There is a constitutional predisposition toward the asthmatic state.

2. In a small percentage of asthmatics, attacks may be produced by individual psychological disorders alone.

3. In a large percentage of asthmatics, attacks may be produced by a combination of allergic or other somatic factors and psychological disorders.

4. The summation of allergic "overloading" may produce psychological disorders which may in turn produce asthmatic attacks in an "asthmatic constitution". 5. The asthma state tends to produce psycholo- 
THE PSYCHOGENIC FACTOR IN ASTHMA

gical disorders of various types which may act independently in the maintenance of further attacks, whether or not the original specific excitant is removed.

6. Therapy of any type must be carried within a definite psychotherapeutic framework to be effective in all cases of asthma. 


\section{BIBLIOGRAPHY}

1. Rackemann, F. M. A Clinical Classification of Asthma Based on a Review of 648 Cases, Amer. J. Med. Sci. 162: 802,1921

2. Ooca, A. F. and Walzer, M. Asthma and Hay Fever, I. C. Thomas, Baltimore, 193, 1931

3. Hansen, K. Allergic and Psychical Factors in Asthma, Proc. Roy. Soc. Med. (Sect. Med.) 22: 25, Apr. 1929

4. Strauss, E. B., Psychogenic Factor in Asthma, Guy's Hosp. Rep. 87; 273, July 1987

5. Hansen, K. Deutsche Med. Wchnschr., 53: 1462, 1927

6. Clarkson, A. H. Nervous Factor in Juvenile Asthma, Brit. Med. J. 2: 845, Oct. 1937

7. Strauss, E. B., The Psychogenic Factor in Asthma: Problems in Methology, Guy's Hosp. Rep. 85: 309, July 1935

8. Brown, W. L. The Problem of Asthma, Proc. Roy. Soc. Med. 16: Pt. 3, 1923

9. Freeman, J. Lancet 1: 288,1928

10.Rolleston, $H$. and Freeman, J., Discussion on the Etiology of Asthma, Proc. Roy. Soc. Med. 28: 247, Jan, 1935

11. Walker, A. L. A Clinical Study of 400 Patients with Bronchial Asthma, Boston Med. and Surg. J. 179: 288, 1918

12. Strecker, E. A. and Ebaugh, F. G. Practical Clinical Psychiatry for Students and Practitioners Ed. IV, Phila. P. Blakiston's Son and Co., 575, 1935

13. Gillespie, R. D. The Psychological Factors in Asthma, Brit. Med. J. 1: 1285, June 1936

14. Wittkower and Petow (trans. by T. P. Sprunt) Ann. Int. Med. V. XII: 13, 334, 1938

15. Waugh, W. F. The Diseases of the Respiratory Organs, G. P. Engelhard and Co., Chicago, 42, 1901

16. Brown, 0. H. Asthma, St Louis, C. V. Mosby Co., 127, 1917

17. Maxwell, J. Analysis of the Asthmatic Patient, Brit. Med. J. 1: 874, May 1936 


\section{BIBLIOGRAPHY}

18. Rogerson, R. H., Hardcastle, D. H. and Duguid, K., The Psycologic Approach to the Problem of Asthma and the Asthma-Bczema-Prurigo syndrome. Guys Hosp. Rep. 85: 289, July 1935

19. Rackemann, F. M. Clinical Allergy, N. Y. MacMilian Co., 390, 1931

20. Kretschmer, E. A Textbook of Medical Psychology, -Transl. by E. B. Strauss, Oxford, 43, 1934

21. Kretschmer, E. Hysteria, Trans. by O. H. Boltz, N. Y. 1926

22. Zelgler, L. H. and Elliot, D. C. Am. J. Med. Sc. 172: 860,1926

23. Gannon, W. B. (from Clarkson) Bodily Changes in Pain, Hunger, Fear or Rage. N. Y. 1929

24. 61 Kholy, M. K. Mental Factors in Bronchial Asthma: Report of Two Cases, Lancet 2: 767, Oct. 1929

25. Wittkower, $\mathbb{E}$. and $\mathbf{E}$. H. Petow, The Psychogenesis of Bronchial Asthma, from Sprunt) Ztschr. F. Klin. Med. 119: 293, 1932

26. Witts, L. G. and Coneybeare, E. T. The Criterion for the Treatment of Bronchial Asthma., Guy's Ho sp. Rep. 85: 138, Apr. 1935

27. Norman (from Houckgeest, A. Q.) Nederl. Tijdschr. V. Geneesk., 1: 1298, 1918 (

28. Norman, Abstract from Houckgeest, J. A. M. A. 7I: 502,1918

29. Kirschbaum, Deutche Med. Wchnschr. 2: 1323, 1920

30. Hofner, Psychlat. Neurol. ges. Breslau July, 1923 Abst. KIIn. Wchnschr. 2: 1778, 1923

31. Gundrum, F. T. Cal. State. J. Med. 19: 258, 1921

32. Hofbauer, L. Asthma von Privatdozent, Julius Springer Wien, 50,1928

33. Feinberg, S. M. Asthma, Hay Fever and Related Dioorders: A Guide for Patients, Lea \& Febiger, Phila. 28, 1933

34. Romer, Deutch. Arch. F. Klin. Med., c/v: 307, 1927.

45. Oberndorff, O. P. Psychogenic Factors in Bronchial Asthma, N. Y. State J. Med. 35: 41, Jan. 1935 


\section{BIBLIOGRAPHY}

36. Imerson, C. P. The Nervous Patient, Phila. 1935

37. Bray, G. W. Recent Advances in Allergy, London, $1937^{\prime}$ (from Clarkson)

38. Freud, S. Interpretation of Dreams, London, 1932 (from Clarkson)

39. Darwin, C. Expression of Emotion in Man and Animals, London, 1890 (from Clarkson)

40. Comri, J. D. History of Scottish Medioine, V.I, London, 1932

42. Watson, J. B. Psychology from the Standpoint of a Behaviorist, Phila. 1920 (from Clarkson)

42. Strauss, E. B. Lancet: 1: 962, 1927

43. Morton, G. F., Childhood Fears, London, 1935

44. Jung, E. G. Psychological Types, London, 1923 (from Clarkson)

45. Hurst, A. F. Pactitioner 123:n 4, 1929

46. Gesell, A. Maturation and Infant Behavior Pattern Hdbk. of Psych. Ed. by Murchison: 209, 1933 (from Clarkson)

47. Blatz, W. E. and Millechamp, D. A. , The Developement of the Bmotion in the Infant, London, 1935 (from Clarkson)

48. Staekel in, Handbuch der Innere. Med. v.2 Pt. 1, Berlin, Julius Springer, 1239, 1930 (from Oberndorff).

49. Stegnamn, A. Zentralblatt Psychoanalyse, v.50, 377,1911 (from Oberndorff)

50. Weisse, E. Psychoanalyze Fines Fables von Nervosen Asthma, Zeitschrift fur Psychonalyse 8: 454, 1922 (from Oberndorff)

51. Loewenstein, J. Med. KIin. 22: 994, 1926 (from Dunbar)

52. Kuttner, A. Deutsche Med. Wchnschr. 51: 1066, 1925

53. Comby, J. Arch. de Med, des Enfants 28: 729, 1925

54. Costa, N. Deutsche Med. Wchnschr. 48: 1373, 1922

55. Schultz, J. H. and Reichmann, F., Deutsche med. Wohnschr. 49: 1081, 1923

56. Moos, E. Munchen. Med. Wchnschr. 70: 805, 1923 (from Dunbar. 


\section{BIBLIOGRAPHY}

57. Marx, E. Deuches Med. Wchnschr. 49: 477, 1923 (from Dunbar)

58. Bartholomew, A. Deutsohe Med. Wchnschr. 48: 1503, 1922

59. Schnelder, A. Zentralbl. f. Inn. Med. 46: 434, 1923

60.Kappis, M. Med. KIin. 20: 1347, 1924

61. Klewitz, F. Kong der Deutsche. Gesellschaft fur Innere Med. in Weisbaden, Apr. 1926: Therap. D. Gegenw. 67: 224, 1926

62. Jelliffe and White, Diseases of the Nervous System, Ed. IV. Lea and Fegiber, 180, 1923

63. Jones, Psychoanalysis Ed. III, Wm. Wood and Co. $428,495,1923$

64. Duke, W. W., Mental and Neurologic Reactions of the Asthma Patient, J. Lab. and Clin. Med. 13: 20, 1927

65. Oppenheim, Textbook of Nervous Diseases; Tn. Foulis, 1123,1911

66. Moll, H. H. Reflex Asthma: Pathology and Treatment Including a Review of 337 Cases, Brit. Med. J. 2: 299, Aug. 1934

67. Feinberg, Asthma Progress: Lit. for 1936. J. Allergy 8; 280, Mar. 1937

68. Fock: Permanent Cure by Means of Psychotherapy, Med. KIIn. 24: 934, June 1928

69. Mayer, R. and Kauffenam, L., Vasoneurotic Diathesis as the underlying cause of Bronchial Asthma 27: 1742, Nov. 1931

70. Ausgelen, P. Psychoneurotic Asthma Deutsche Med. Wchnschr. 59: 1508, Sept. 29, 1933

71. Holub, A. Internat. Ztschr. F. Individualpsychel. 11: 216, May-June, 1933

72. Hanse, A. The Psychoneurotic aspects of Bronchial Asthma, Nervenarzt 7: 17, 1934

73. Dekker, H. Is There A Nervous Asthma? Munchen. Med, Wchnschr. 81: 323, Mar, 1934

74. Bogolepov, N. K. Evaluation of the Neuropsychic Element in Bronchial Asthma, Klin. Med. \#2, 12: 202,1934

75. Galup. P. Asthma of Psychic Origin: 3 Cases, Gaz. Med. de France 44: 403, Apr. 1937 


\section{BIBLIOGRAPHY}

76. Edel, H. Bronchial Asthma as a Hysteric Psychosis: 2 Cases, Med. Klin. 29: 322, Mar. 1933

77. Salter, H. H. On Asthma, N. Y. Wm. Wood and Co. 1882,78

78. Swinny, B, Multiplicity of Factors in Bronchial Asthma, Texas State J. Med. 29: 321, Sept. 1933

79. Fraenkel, E. M. Asthmatic "Disposition" and specific Allergen, Brit. Med. J. 1: 438, Feb. 1937

80. Williams, C. B. J. and Clymer, Merideth, Diseases of the Respiratory Organs, Phila., Lea and Blanchard, 474, 1845

81. Dejernie and Gauckler, Psychoneurosis and Psychotherapy, Ed. II J. B. Lippincott, 86, 1915

82. Fordyce, A. D. Lancet 1: 175, 1923

83. Brown, J. J. G. A Note On Asthma: Its Pathology and Treatment, Edinburgh Med. J. 88: 54, 1922

84. Dunbar, H. F. Emotion and Bodily Changes: A survey of the Literature on Psychosomatic Relationship. 1910-1933. Columbia Univ. Press, N. Y. 595, 1935

85. Naber, J. Asthma Bronchiale: Allergische Behandlung und Psychotherapie, Therap. d. Gegenw., 70: 437, 1929

86. Laudenheimer, R. Hypnotische Nebungstherapie des Bronchial Asthma, Therap. d. Gegenw. 67: 339, 1926

87. Reichmann, F. Zur Psychopathologie des Asthma Bronchiale Med. Klin. 18: 1066, 1922 (From Dunbar)

88. Marcinowsk1, J. Die Heilung eines Schweren Fables Asthma durch Psychoanalyse. Jahrb. F. Psychoanalyt. Forschungen, 5: 529, 1913 (From Dunbar)

89. Fenichel, Otto, Hysterien und Zwangsneurosen. Psychoanalytische Spezielle Neurosenlehre, Wien: Internat. Psychoanalyt. Verlag. 193, 1931 (From Dunbar)

90. Saenger, M. Neber Asthma und Seine Behandlung. Berlin: Karger, 82, 1910 (From Dunbar)

91. Brugelmann, R. Das Asthma, Sein Wesen und seine Behandlung, auf Grund Zweisendreissigjahriger Erfahrungen und Forshungen dargestellt. Weisbaden; Bergmann, 5. Vermehrte Auf1. 267, 1910 (Fom Dunbar) 